\title{
Iodine Atom Loss Kinetics in Internal Energy Selected 1-Iodoalkane Cations by Imaging Photoelectron Photoion Coincidence Spectroscopy
}

Tyson G. Rowland§, Sampada Borkar§, Andras Bodi ${ }^{\dagger}$, and Bálint Sztáray§,*

$\S$ Department of Chemistry, University of the Pacific, Stockton, California 95211

${ }^{\dagger}$ Molecular Dynamics Group, Paul Scherrer Institut, Villigen 5232, Switzerland

\begin{abstract}
Imaging photoelectron photoion coincidence (iPEPICO) spectroscopy has been used to determine $0 \mathrm{~K}$ appearance energies for the unimolecular dissociation reactions of several energy selected straight chain alkyl iodide cations $1-\mathrm{C}_{n} \mathrm{H}_{2 n+1} \mathrm{I}^{+} \rightarrow \mathrm{C}_{n} \mathrm{H}_{2 n+1}{ }^{+}+\mathrm{I}^{\cdot},(n=3-7)$. The $0 \mathrm{~K}$ appearance energy of iodine atom loss, yielding in fact the 2-alkyl radical cation up to $n=6$, was determined to be $9.836 \pm 0.010,9.752 \pm 0.010,9.721 \pm 0.010,9.684 \pm 0.010$ and $9.688 \pm 0.015$ $\mathrm{eV}$ in $1-\mathrm{C}_{3} \mathrm{H}_{7} \mathrm{I}, 1-\mathrm{C}_{4} \mathrm{H}_{9} \mathrm{I}, 1-\mathrm{C}_{5} \mathrm{H}_{11} \mathrm{I}, 1-\mathrm{C}_{6} \mathrm{H}_{13} \mathrm{I}$, and $1-\mathrm{C}_{7} \mathrm{H}_{15} \mathrm{I}$, respectively. In 1-iodohexane and the smaller molecules, these correspond to the transition state along the 1-iodoalkane cation $\rightarrow 2$ iodoalkane cation reaction path, and can be used in conjunction with isodesmic reaction energies to determine the reverse barriers to dissociative photoionization. The small kinetic shift is indicative of little $\mathrm{H}$ tunneling during isomerization. Directly computed reverse barriers show that run-of-the-mill computational approaches are of limited use when applied to open shell systems containing period 5 elements. Hindered rotors were found to play a minor role in the internal energy distribution and the dissociation rate constants.
\end{abstract}

\footnotetext{
* Corresponding author at: University of the Pacific, Department of Chemistry, 3601 Pacific Ave, Stockton, CA 95211, USA. Tel: +1 (209) 946-2654.

Email address: bsztaray@pacific.edu
} 


\section{Introduction}

It has been documented both experimentally ${ }^{1,2}$ and, more recently, by quantum chemical calculations $^{3-7}$ that halogen-carbon bond strengths decrease with increasing halogen atom size from $\mathrm{F}>\mathrm{Cl}>\mathrm{Br}>\mathrm{I}$. The fragileness of the $\mathrm{C}-\mathrm{I}$ bond has been put to good use in producing short-lived radicals for gas-phase experiments and in synthetic chemistry. ${ }^{8,9}$ Iodine's outstanding leaving group character in the presence of a nucleophilic reactant makes it an attractive ligand in $\mathrm{S}_{\mathrm{N}} 2$ type substitutions. ${ }^{10}$ The dissociation of a carbon-iodine bond, however, is not always just a simple bond-breaking reaction, as Rosenstock et al. recognized three decades ago. Even though the potential well in the 1-iodopropane cation is less than $60 \mathrm{~kJ} \mathrm{~mol}^{-1}$ deep, the fragment ion is not the 1-propyl cation, but rather the 2-propyl cation, after isomerization. ${ }^{11}$ Thus, however weak the $\mathrm{C}-\mathrm{I}$ bond may be, alternative reaction paths to simple bond rupture may still arise even in barely bound ionic systems.

Recent advances in quantum chemistry have made calculating thermochemical properties of small molecules and ions more accessible, while also contributing to more accurate and complete thermochemical data. ${ }^{12-17}$ Iodine-atom loss was found to be accompanied by different translational energy distributions in diiodoethylene and diiodoethane cations. ${ }^{18}$ Preliminary calculations and a more detailed exploration ${ }^{19}$ of the potential energy surface of $\mathrm{C}_{2} \mathrm{H}_{4} \mathrm{I}_{2}^{+}$ illustrated the computational challenges, notably the role of spin-orbit coupling in describing open shell systems containing iodine. Dissociative photoionization experiments using photoelectron photoion coincidence (PEPICO) spectroscopy are one of the few ways to measure dissociative photoionization onsets with an accuracy approaching $1 \mathrm{meV}\left(0.1 \mathrm{~kJ} \mathrm{~mol}^{-1}\right)$ in favorable cases, ${ }^{20-22}$ which, by providing benchmark values, can contribute to quantum chemical methods development for experimentally and computationally challenging systems. 
It is in this regard that the dissociative photoionization of 1-iodoalkanes are of particular interest. In $\mathrm{C}-\mathrm{I}$ bond breaking dissociative photoionization reactions, both products, i.e. the closed shell organic fragment ion and the iodine atom, may be reasonably well known and no open shell species is involved in the reaction energy to challenge theory. However, as will be shown later, straight chain 1-iodoalkanes yield 2-alkyl cations over an isomerization transition state, the energy of which can be accurately measured in PEPICO experiments. This means that the measured activation barriers shall be useful computational benchmarks for transition state calculations. Along with the adiabatic ionization energies, also available experimentally for molecules with little geometry change upon ionization, they provide accurate and rare experimental anchor points for computational chemistry.

In this study, we performed imaging PEPICO (iPEPICO) experiments to study I loss in 1$\mathrm{C}_{3} \mathrm{H}_{7} \mathrm{I}^{+}$through $1-\mathrm{C}_{7} \mathrm{H}_{15} \mathrm{I}^{+}$. The iodine-atom loss threshold in the dissociative photoionization of the two smaller iodoalkanes, iodomethane and iodoethane, has been reported previously using iPEPICO and a TPEPICO experiment, respectively. ${ }^{23,24}$ These studies, along with literature thermochemistry data on the dissociative photoionization energy of iodopropane, have established accurate thermochemical onsets, which can be used in conjunction with isodesmic reaction energy calculations involving closed-shell species, $\mathrm{RH}+\mathrm{R}^{\prime^{+}} \rightarrow \mathrm{R}^{+}+\mathrm{R}^{\prime} \mathrm{H}$ and $\mathrm{RI}+\mathrm{R}^{\prime} \mathrm{H}$ $\rightarrow \mathrm{RH}+\mathrm{R}^{\prime} \mathrm{I}$ to obtain the threshold of I loss from longer chain alkanes.

Rosenstock et al. ${ }^{11}$ reported the threshold dissociative photoionization onset $\left(E_{0}\right)$ for the iodine atom loss in 1-propyl iodide to be $9.84 \pm 0.01 \mathrm{eV}$. This energy is in a Frank-Condon gap of the photoelectron spectrum, which makes non-threshold ionization experiments difficult. They also found the parent molecular ion to be metastable, and reported that the dissociation is accompanied by significant kinetic energy release (KER). They concluded that the main reason 
for the metastability of the parent ion could be an overall reverse barrier to dissociation, and the formation of the more stable 2-propyl instead of the 1-propyl cation at threshold. Therefore, they could only determine an upper limit to the heat of formation of the $1-\mathrm{C}_{3} \mathrm{H}_{7}^{+}$cation, at $822 \pm 5$, and $805 \pm 5 \mathrm{~kJ} \mathrm{~mol}^{-1}$ at $0 \mathrm{~K}$ and $298 \mathrm{~K}$, respectively. Based on the kinetic energy release, they also determined the $0 \mathrm{~K}$ heat of formation of $2-\mathrm{C}_{3} \mathrm{H}_{7}^{+}$to be $816.2 \pm 4 \mathrm{~kJ} \mathrm{~mol}^{-1}$. In a similar study, Brand and Baer looked at the kinetic energy release distribution of I-loss alkyl cations from 1and 2-iodopropane ions using the PEPICO technique. ${ }^{25}$ From kinetic energy release data, they confirmed that the product of iodine-loss dissociation from $1-\mathrm{C}_{3} \mathrm{H}_{7} \mathrm{I}^{+}$is the 2-propyl cation, and that the isomerization of $1-\mathrm{C}_{3} \mathrm{H}_{7} \mathrm{I}^{+}$to $2-\mathrm{C}_{3} \mathrm{H}_{7} \mathrm{I}^{+}$takes place prior to dissociation. At higher internal energies, however, the direct dissociation to $1-\mathrm{C}_{3} \mathrm{H}_{7}{ }^{+}$was suggested to be faster than the isomerization channel, thus outcompeting the rearrangement process yielding $2-\mathrm{C}_{3} \mathrm{H}_{7}^{+}$.

Oliveira et al., from the same group, ${ }^{26}$ reported the $0 \mathrm{~K}$ threshold for $1-\mathrm{BuI} \rightarrow \mathrm{Bu}^{+}+\mathrm{I}+$ $\mathrm{e}^{-}$as $9.74 \pm 0.02 \mathrm{eV}$. The study concludes that the dissociation proceeds via a reverse barrier, even though the kinetic energy release is relatively small, but the onset energies from the 1haloalkanes cannot be used to derive the heat of formation of the 2-butyl cation. Similarly to the case of iodopropane, they conclude that 1-iodobutane dissociates into the 2-butyl isomer cation by $\mathrm{H}$ atom transfer before the iodine atom leaves. They propose the following mechanism:

$$
\mathrm{CH}_{3} \mathrm{CH}_{2} \mathrm{CH}_{2} \mathrm{CH}_{2} \mathrm{X}^{+} \rightarrow \mathrm{CH}_{3} \mathrm{CH}_{2} \mathrm{CHXCH}_{3}^{+} \rightarrow \mathrm{CH}_{3} \mathrm{CH}_{2} \mathrm{C}^{+} \mathrm{HCH}_{3}+\mathrm{X} \text {, }
$$

supported by low-level ab initio calculations.

Park et al. have used vacuum-ultraviolet mass-analyzed threshold ionization (MATI) to study 1-propyl and 1-butyl iodide and discussed their thermochemistry at length. They reported 0 $\mathrm{K}$ appearance energy of I loss in 1-propyl iodide to be $9.8332 \pm 0.0017 \mathrm{eV} .^{27}$ The metastable ion dissociation spectrum obtained with a double focusing mass spectrometer was used to estimate 
the dissociation rate constant of 1-iodopropane ion in the threshold region to be $10^{4}-10^{5} \mathrm{~s}^{-1} .^{27}$ Because the 1-propyl and cyclopropane isomer cations are significantly higher in energy, this study agrees that the dissociation occurs by isomerization to the 2-iodopropane cation, with subsequent dissociation of this species into the 2-propyl cation. The analogous result on 1iodobutane was a 2-butyl cation appearance energy at $E_{0}\left(2-\mathrm{Bu}^{+}\right)=9.7544 \pm 0.0045 \mathrm{eV},{ }^{28}$ in good agreement with the PEPICO study of Oliveira et al. ${ }^{26}$ So far, there are no published studies that report dissociative ionization thresholds of iodopentane, iodohexane, or iodoheptane.

With respect to neutral thermochemistry of iodoalkanes, Mortimer et al. ${ }^{29}$ reported $\Delta_{\mathrm{f}} H^{\ominus}{ }_{298 \mathrm{~K}}(1-\mathrm{PrI})=-29.7 \pm 7.5 \mathrm{~kJ} \mathrm{~mol}^{-1}$ by calorimetry, while Stull et al. ${ }^{30}$ later gave $\Delta_{\mathrm{f}} H^{\ominus}{ }_{298 \mathrm{~K}}(1-$ PrI $)=-30.5 \mathrm{~kJ} \mathrm{~mol}^{-1}$. A thermochemical review of iodoalkyl species by Richard and Gaona ${ }^{31}$ reports $\Delta_{\mathrm{f}} H_{298 \mathrm{~K}}^{\ominus}$ values of $-27.8,-48.5,-60.1,-89.7$, and $-110.3 \mathrm{~kJ} \mathrm{~mol}^{-1}$ for 1-PrI, 1-BuI, 1PenI, 1-HexI, and 1-HepI, respectively, taken partly from the literature and partly derived by using group additivity calculations. ${ }^{32}$ Benson and Amano reported $\Delta_{\mathrm{f}} H^{\ominus}{ }_{298 \mathrm{~K}}(1-\mathrm{BuI})=-50.2 \mathrm{~kJ}$ mol $^{-1}$ using the $\mathrm{CH}_{2}$ additivity rule. ${ }^{33}$

Adiabatic ionization energies $\left(I E_{\mathrm{ad}}\right)$ are needed to convert dissociative photoionization thresholds to potential energy well depths, i.e. activation energies in the cation. In propyl iodide, photoelectron spectroscopy (PES) was used to obtain $I E_{\mathrm{ad}}$ as $9.26 \pm 0.01 \mathrm{eV}^{34,35,36}$ and more recently as $9.25 \mathrm{eV}$ by Novak et al., ${ }^{37}$ and as $9.28 \mathrm{eV}$ by Luo and Pacey. ${ }^{38}$ Studies on butyl iodide confirm a decreasing $I E_{\mathrm{ad}}$ trend with most photoelectron spectroscopy (PES) studies agreeing on an $I E_{\text {ad }}$ value of $9.23 \pm 0.01 \mathrm{eV},^{25,34,35,37,39}$ while the PEPICO study by Oliveira et $a l .^{26}$ yielded $I E_{\mathrm{ad}}=9.21 \pm 0.01 \mathrm{eV}$. The $I E_{\mathrm{ad}}$ of pentyl iodide was found to be $9.18 \pm 0.01,{ }^{34}$ $9.20,{ }^{35}$ and $9.22 \mathrm{eV}^{37}$ from photoelectron spectroscopy. For hexyl iodide, Boschi and Salahub ${ }^{35}$ 
established an $I E_{\text {ad }}$ of $9.20 \mathrm{eV}$, while Novak $^{37}$ lists $9.19 \mathrm{eV}$, both by PES. The only heptyl iodide $I E$ study by Novak et al. ${ }^{37}$ reports $9.17 \mathrm{eV}$ as the $I E_{\mathrm{ad}}$.

\section{Experimental}

Samples 1- $\mathrm{C}_{3} \mathrm{H}_{7} \mathrm{I}$ and $1-\mathrm{C}_{4} \mathrm{H}_{9} \mathrm{I}$ were purchased from TCI America, 1- $\mathrm{C}_{5} \mathrm{H}_{11} \mathrm{I}$ and $1-\mathrm{C}_{6} \mathrm{H}_{13} \mathrm{I}$ from Sigma-Aldrich, and $1-\mathrm{C}_{7} \mathrm{H}_{15} \mathrm{I}$ from Alfa-Aesar. All samples were marked as over 98.0\% purity and used without further purification. Experimental data were collected at the VUV beamline $^{21}$ of the Swiss Light Source, Paul Scherrer Institut, on the Imaging Photoelectron Photoion Coincidence (iPEPICO) endstation. Detailed description of the instrument and technique can be found elsewhere ${ }^{20,40-43}$ and only a brief overview is given here. The gas-phase sample was effusively introduced into the ionization region at room temperature through a $30 \mathrm{~cm}$ long, $6 \mathrm{~mm}$ o.d. Teflon tube. The typical pressure in the experimental chamber was $1-7 \times 10^{-6}$ mbar during measurements. Monochromatic synchrotron radiation was used to ionize the sample in a less than $2 \times 2 \mathrm{~mm}$ interaction region. The photon energy was calibrated using $\mathrm{Ar}$ autoionization lines, $11 s^{\prime}$ at $15.7639 \mathrm{eV}$ and $12 s^{\prime}$ at $15.7973 \mathrm{eV},{ }^{44}$ in first and second order. A constant $120 \mathrm{~V} \mathrm{~cm}^{-1}$ electric field accelerates the photoelectrons and photoions in opposite directions. The electrons are velocity map imaged onto a Roentdek DLD40 position sensitive delay-line detector with kinetic energy resolution better than $1 \mathrm{meV}$ at threshold. Photoions are space focused and detected in delayed coincidence by a Jordan TOF C-726 microchannel plate detector after being analyzed by a two-stage Wiley-McLaren time-of-flight mass spectrometer with a $5.5 \mathrm{~cm}$ long first and a $1 \mathrm{~cm}$ long second acceleration region and a $55 \mathrm{~cm}$ drift region. The multiple-start/multiple-stop data acquisition technique eliminates signal paralysis and allows for measurements at high ionization rates. ${ }^{45}$ The non-threshold, "hot," electron contamination of the threshold electron signal at the center of the image was approximated by and subtracted based on 
the average count rate in a ring area surrounding the center spot of the detector. ${ }^{40}$ Photoions were thus internal energy selected by correlating only the ions that were in delayed coincidence with the corrected threshold electron signal.

\section{Data analysis}

The (hot-electron subtracted) total threshold electron signal can be plotted as a function of the photon energy to obtain the threshold photoelectron spectrum (TPES). The fractional parent and fragment ion abundances in threshold photoionization as a function of the photon energy yield the breakdown diagram, shown in Figure 1, which is independent of sample pressure, photon intensity and, to a large extent, Frank-Condon factors. ${ }^{22}$

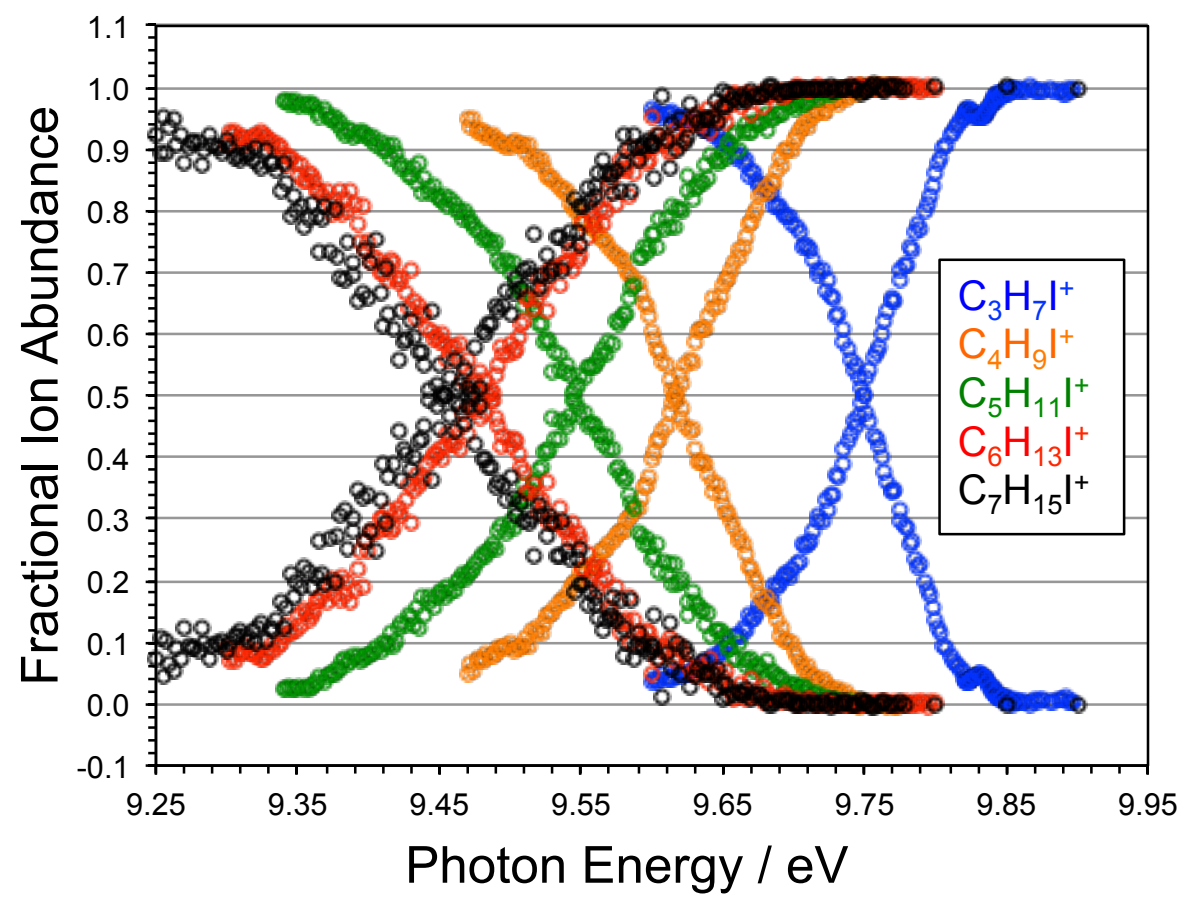

Figure 1. Breakdown diagrams for $1-\mathrm{C}_{3} \mathrm{H}_{7} \mathrm{I}^{+}$(blue), $1-\mathrm{C}_{4} \mathrm{H}_{9} \mathrm{I}^{+}$(orange), $1-\mathrm{C}_{5} \mathrm{H}_{11} \mathrm{I}^{+}$(green), 1 $\mathrm{C}_{6} \mathrm{H}_{13} \mathrm{I}^{+}$(red), and $1-\mathrm{C}_{7} \mathrm{H}_{15} \mathrm{I}^{+}$(black) showing the fractional abundances of the parent ion and the daughter ion(s). 
The parent ions were found to be metastable close to the I-loss dissociative photoionization threshold, as indicated by the slightly asymmetric daughter ion time-of-flight distributions, shown in Figure 3. To extract absolute dissociation rates, the TOF distributions were modeled using ion optics parameters and statistical rate theory considering the internal energy distribution of the neutral precursor molecules and the ions. ${ }^{46}$ The model parameters were obtained from density functional theory (DFT) calculations using the Gaussian 09 package, as described in the quantum chemical section below.

The internal energy distribution of the parent ion corresponds to the thermal energy distribution of the neutral, shifted by the difference of the photon energy and the adiabatic ionization energy and slightly broadened by the combined photon and electron energy resolution of about $3 \mathrm{meV}$. The thermal energy distribution of the neutral molecules is calculated using the rovibrational density of states calculated based on ab initio rotational constants and vibrational frequencies by the direct count method. ${ }^{47,48}$ RRKM theory was used to calculate the unimolecular rate constants of the ionic dissociation reactions using Eq. 4, where $N^{\ddagger}\left(E-E_{0}\right)$ is the sum of states at the transition states and $\rho(E)$ is the density of states of the ion measured from the bottom of the ion potential energy well. ${ }^{49-51}$ The symmetry parameter $\sigma$ is unity for all iodine-loss dissociation reactions of the alkyl iodide molecular ions.

$$
k(E)=\frac{\sigma N^{\ddagger}\left(E-E_{0}\right)}{h \rho(E)}
$$

In the fitting procedure, the dissociation limit and the transitional vibrational frequencies of the TS were adjusted to reproduce the TOF distributions and the breakdown diagram as well as possible. This procedure, along with the computer code that models the PEPICO experiment, has been described earlier. ${ }^{22}$ 


\section{Quantum chemical calculations}

Rotational constants and vibrational frequencies were obtained from density functional theory (DFT) calculations at the $\omega$ B97X-D/cc-pVTZ level of theory with the 46-electron quasirelativistic Stuttgart effective core potential on iodine. ${ }^{52-54}$ The transition states for the $1-\mathrm{RI}^{+} \rightarrow$ $2-\mathrm{RI}^{+}$isomerization reaction have been located using bond length scans and the Synchronous Transit-Guided Quasi-Newton method. ${ }^{55}$ Once the transition state was found in propyl iodide (see Figure 2), the geometry of the $\mathrm{C}_{2} \mathrm{H}_{3} \mathrm{I}$ active site was frozen, and a methyl group was added to the carbon chain and the ion geometry was optimized. The resulting structure was close enough to the stationary point that mode following could be used to locate the butyl, pentyl, hexyl, and heptyl isomerization transition states. The rotational constants and vibrational frequencies were then used as input parameters for the statistical modeling and the transitional modes of the transition states were scaled so that the RRKM rate curves agreed with the measured ones.

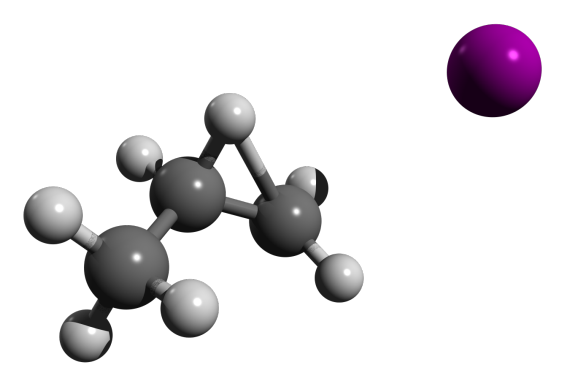

Figure 2. DFT-optimized transition state structure for the 1-iodopropane $\rightarrow$ 2-iodopropane rearrangement in the cation.

In order to complement the appearance energies thus derived, we carried out further geometry optimizations and vibrational analyses for the neutrals as well as the corresponding alkanes not only using DFT, but also second-order Møller-Plesset perturbation theory (MP2). These were used to calculate the $0 \mathrm{~K}$ reaction energies for the $\mathrm{RI}+\mathrm{R}^{\prime} \mathrm{H} \rightarrow \mathrm{RH}+\mathrm{R}^{\prime} \mathrm{I}$ processes, 
where $\mathrm{R}=\mathrm{Me}$, Et, $\mathrm{Bu}, \mathrm{Pe}, \mathrm{Hex}$ and Hep. More accurate, composite method calculations were used to address the isodesmic reaction energies for the analogous $\mathrm{RH}+\mathrm{R}^{\prime+} \rightarrow \mathrm{R}^{+}+\mathrm{R}^{\prime} \mathrm{H}$ reactions, such as CBS-QB3, CBS-APNO, and G4 ${ }^{56-58}$ The sum of two such reaction energies corresponds to $\mathrm{RI}++\mathrm{R}^{\prime^{+}} \rightarrow \mathrm{R}^{+}+\mathrm{R}^{\prime} \mathrm{I}$, which in turn is the difference of the dissociative photoionization energies, $\mathrm{R} / \mathrm{R}^{\prime} \mathrm{I}+h v \rightarrow \mathrm{R} / \mathrm{R}^{\prime+}+\mathrm{I}+\mathrm{e}^{-}$. Since the methyl and ethyl iodide dissociative photoionization energies have previously been measured accurately, ${ }^{23,24}$ and there is literature data to calculate the endothermicity of the 1-PrI $+h v \rightarrow 2-\operatorname{Pr}^{+}+\mathrm{I}+\mathrm{e}^{-}$process, the analogous energies for larger alkyl iodides can be calculated, and compared with the measured dissociative photoionization thresholds to determine the reverse barriers, as well, as shown in Scheme 1.

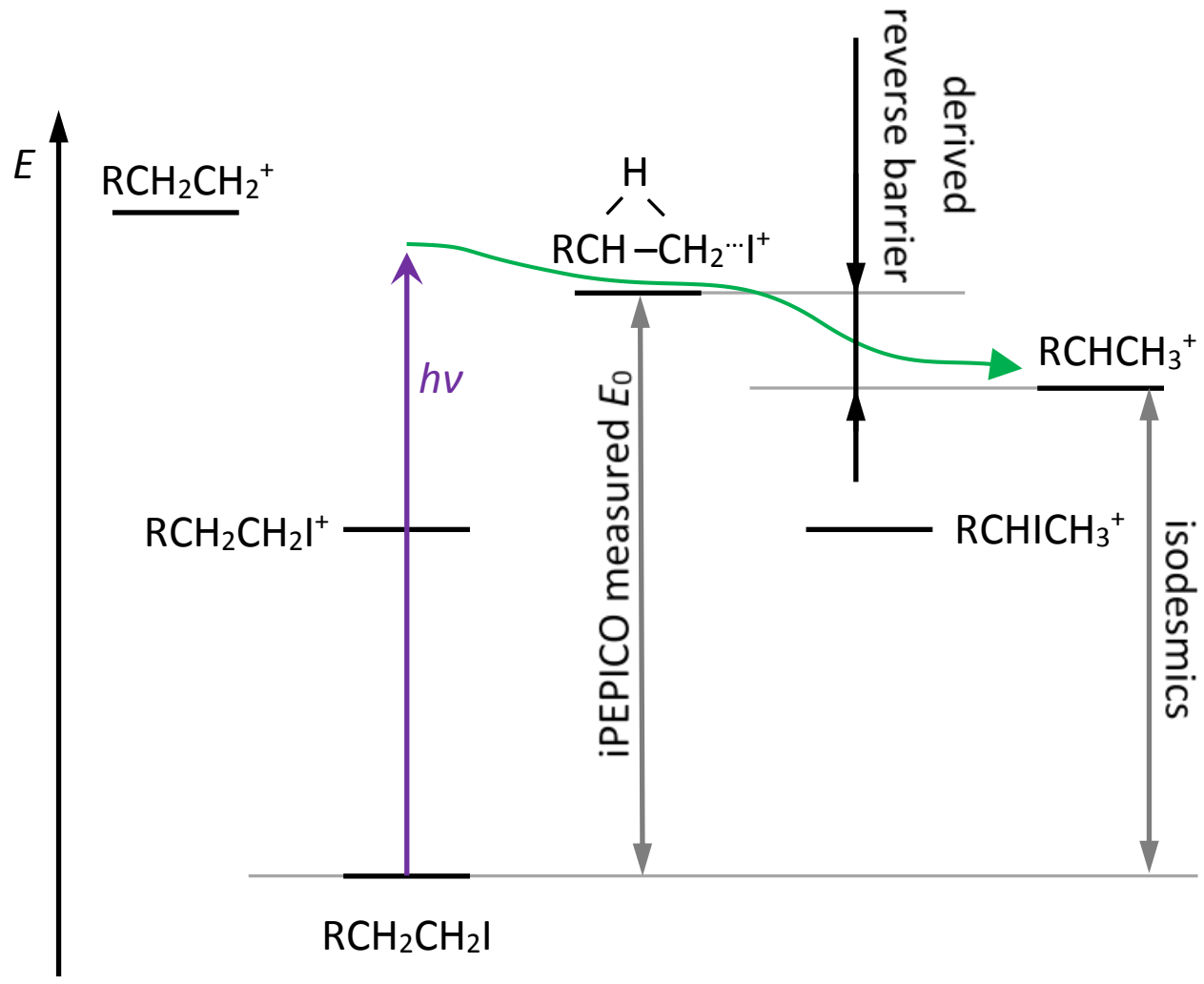

Scheme 1. Energy diagram showing the I-loss dissociative photoionization process in iodoalkanes. The reverse barrier height is obtained as difference between the measured $E_{0}$ with the reaction energy determined based on isodesmic reaction energy calculations. 
DFT and MP2 open-shell energetics results for ionization energies, dissociative photoionization thresholds and reverse barriers can also be directly compared with the energetics derived based on the experimental appearance energies and isodesmic reaction energy calculations.

\section{Results and discussion}

Time-of-flight spectra of energy selected $1-\mathrm{C}_{3} \mathrm{H}_{7} \mathrm{I}^{+}(m / z=170), 1-\mathrm{C}_{4} \mathrm{H}_{9} \mathrm{I}^{+}(m / z=184), 1-$ $\mathrm{C}_{5} \mathrm{H}_{11} \mathrm{I}^{+}(m / z=198)$, and $1-\mathrm{C}_{6} \mathrm{H}_{13} \mathrm{I}^{+}(m / z=212)$ molecular ions and their iodine-loss fragment ions were collected in the 9.3-9.9 eV photon energy range. Representative low-energy TOF distributions are shown in Figure 3, and the I-loss breakdown diagrams are plotted in Figures 1 and $4 \mathrm{a}-\mathrm{d}$. It is evident from the asymmetric daughter ion peaks in time-of-flight spectra that all four molecular ions have a slightly metastable parent ion at threshold, i.e. the iodide atom loss is "slow" on the timescale of the experiment, $k\left(E_{0}\right)<10^{7} \mathrm{~s}^{-1}$.
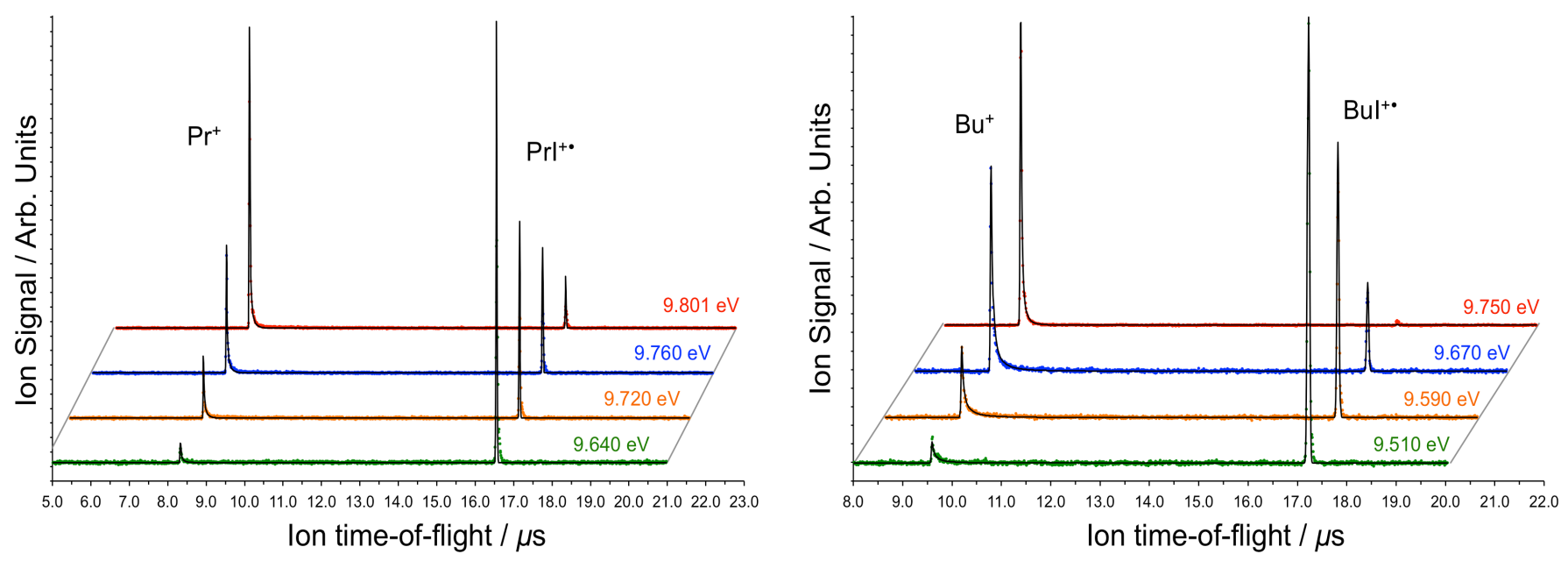

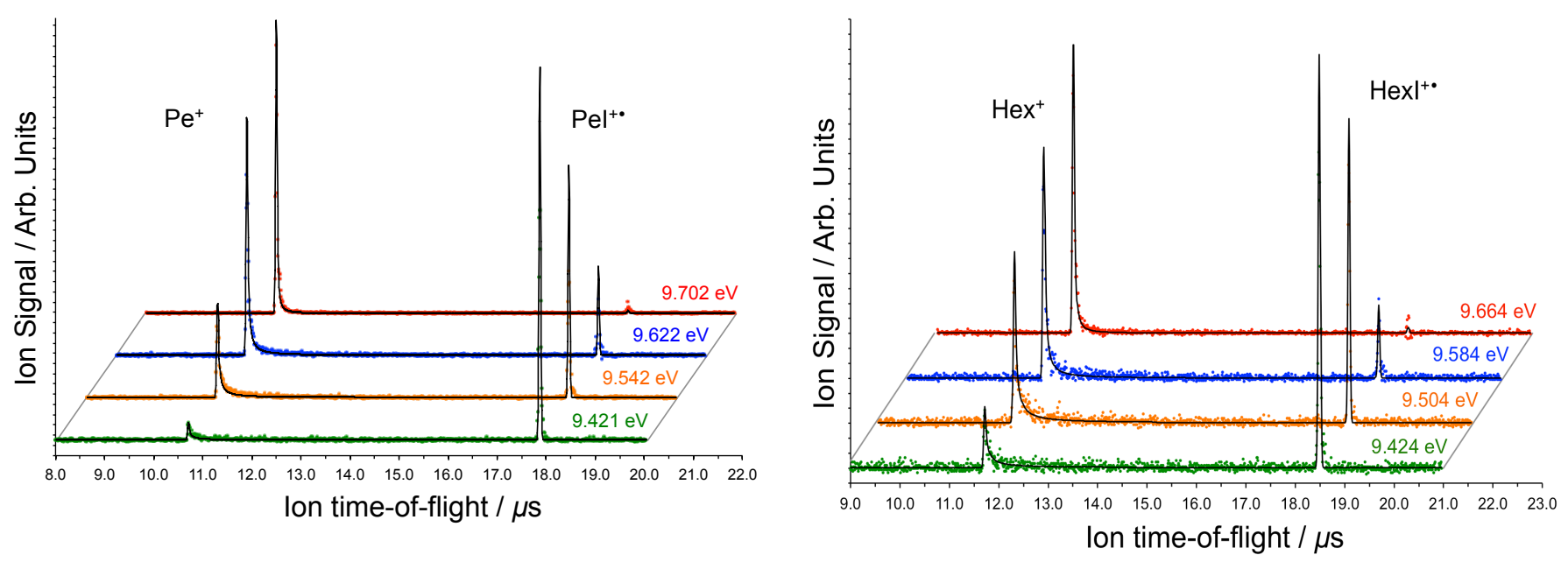

Figure 3. Time-of-flight spectra of energy selected alkyl iodide cations, a) 1-iodopropane, b) 1-iodobutane,

c) 1-iodopentane, and d) 1-iodohexane. Points are experimental data and solid black lines show the RRKM modeled TOF distributions.

Furthermore, by comparing the four breakdown curves it can be seen that as the alkyl moiety gets larger, the appearance energy of the respective alkyl cation shifts to lower energy. The crossover energy, corresponding to $50 \%$ parent and daughter ion abundance in the breakdown diagram, shifts to lower energy by $0.13 \mathrm{eV}$ from iodopropane to iodobutane, and by about $0.06-$ $0.07 \mathrm{eV}$ for each additional carbon in the chain of the series up to iodohexane. From iodohexane to iodoheptane, the shift in the crossover energy is about half this amount and the shift in the parent ion disappearance energy (in the case of no kinetic shift this corresponds to the $0 \mathrm{~K}$ appearance energy) seems even smaller than this. For comparison, the crossover energy for $\mathrm{C}_{2} \mathrm{H}_{5} \mathrm{I}^{+} \rightarrow \mathrm{C}_{2} \mathrm{H}_{5}^{+}+\mathrm{I}+\mathrm{e}^{-}$, at $10.49 \mathrm{eV}$ at room temperature, is $0.74 \mathrm{eV}$ higher than that of 1-PrI, ${ }^{24}$ whereas the crossover energy for iodine atom loss from methyl iodide at about $12.20 \mathrm{eV}$ is 1.71 $\mathrm{eV}$ higher than that of ethyl iodide. ${ }^{23}$ It is also evident that the width of the breakdown diagram increases with increasing alkyl chain length, as the room temperature thermal energy distribution of the neutral precursor molecules and, therefore, that of the molecular ions becomes broader, due to the increasing number of degrees of freedom. 
Propyl iodide. In the smallest iodoalkane studied herein, the RRKM model of the iodopropane breakdown curve and time-of-flight distributions yields a $0 \mathrm{~K}$ appearance energy of $E_{0}=9.836 \pm 0.010 \mathrm{eV}$, in good agreement with the value proposed by Park et al. ${ }^{27}$ of $9.8332 \pm$ $0.0017 \mathrm{eV}$ using MATI and with the Rosenstock et al. ${ }^{11}$ value of $9.84 \pm 0.01$ using a lowerresolution PEPICO experiment. The model temperature corresponding to the best fit was somewhat lower than room temperature, at $274 \mathrm{~K}$ (vide infra). This value, which affects the slope of the breakdown curve, was still well within the $\pm 10 \%$ range suggested by Baer et al. ${ }^{18}$ Furthermore, the quality of the RRKM fit was not considerably worse with a room-temperature model, either. Extrapolated dissociation rate at threshold was found to be $9.5( \pm 0.5) \times 10^{6} \mathrm{~s}^{-1}$. There is an interesting feature in the breakdown curve, a very noticeable "bump" in the ion fractional abundance close to the $E_{0}$, coinciding with a peak in the TPES signal, as shown in Figure $4 \mathrm{a}$. Such an effect has also been observed in iodomethane, ${ }^{23}$ where the TPES peaks showed up as bumps in the parent ions abundance at the corresponding energy of the breakdown diagram. This suggests that the threshold photoionization cross-section in iodopropane at 9.84 $\mathrm{eV}$ is larger for (rotationally) cold molecules, and the resulting photoion internal energy distribution has a lower mean internal energy than would be expected assuming internal energy independent photoionization cross-sections.

Butyl iodide. The appearance energy of the butyl cation from butyl iodide was found to be $9.752 \pm 0.010 \mathrm{eV}$, based on the RRKM modeling shown in Figure $4 \mathrm{~b}$. This $E_{0}$ value agrees well with the value obtained by Oliveira et $_{\text {al }}{ }^{26}$ at $9.74 \pm 0.02 \mathrm{eV}$, and the Park et al $^{27}$ value of $9.7544 \pm 0.0045 \mathrm{eV}$. Similarly to the case of propyl iodide, the optimal model temperature was below room temperature, but to a lesser extent, at $285 \mathrm{~K}$. Extrapolated dissociation rate at threshold was found to be $1.1( \pm 0.2) \times 10^{6} \mathrm{~s}^{-1}$. Again, peaks in the TPES show up as parent ion 
bumps in the breakdown diagram. The very large TPES peak just at slightly higher energy than $E_{0}$ is less of an influence, as it does not affect the breakdown curve. However, the two other, minor peaks between 9.5 and $9.6 \mathrm{eV}$ cause the parent ion ratio to increase and result in small oscillations in the breakdown curve. These regions were excluded from the model in the fitting procedure to provide a better fit in the unaffected parts of the breakdown curve.

Pentyl and hexyl iodide. RRKM modeling of the breakdown curves and TOF distributions yielded I-loss $E_{0}$ values of $9.721 \pm 0.010 \mathrm{eV}$ for $\mathrm{C}_{5} \mathrm{H}_{11} \mathrm{I}$ and $9.684 \pm 0.010 \mathrm{eV}$ for $\mathrm{C}_{6} \mathrm{H}_{13} \mathrm{I}$, which are, to the best of our knowledge, the first reported thresholds for these processes. In the modeling of these two experiments, the optimized temperatures were consistently somewhat higher than room temperature and consistently rising model temperatures were found with increasing alkyl chain length starting from propyl iodide. Extrapolated dissociation rate at threshold was found to be $9.2( \pm 0.6) \times 10^{4} \mathrm{~s}^{-1}$, and $8( \pm 2) \times 10^{3} \mathrm{~s}^{-1}$, respectively. As seen in Figures $4 \mathrm{c}-\mathrm{d}$, the threshold photoelectron signal exhibited smaller variations in the photon energy range of interest and the breakdown curves show no features that are attributed to the TPES signal fluctuations.

a)

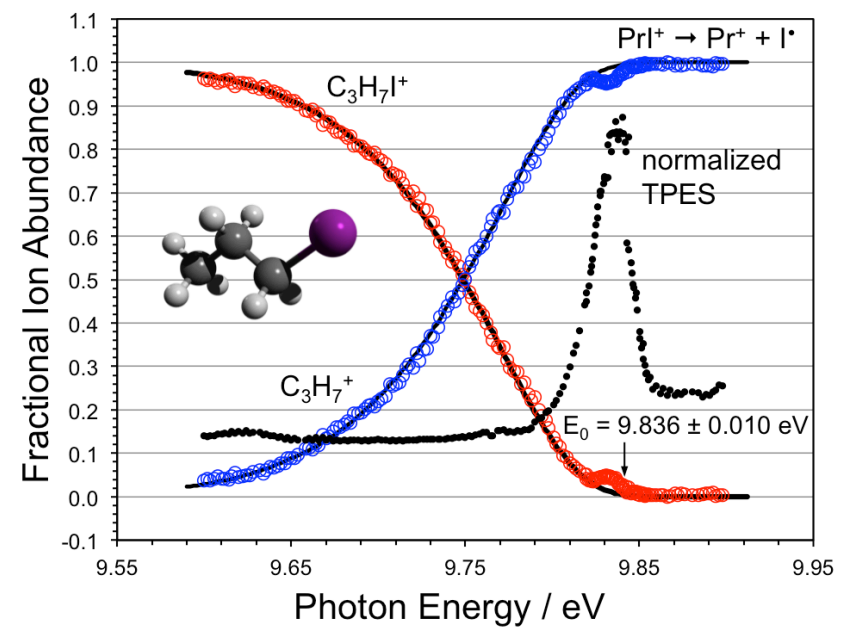

b)

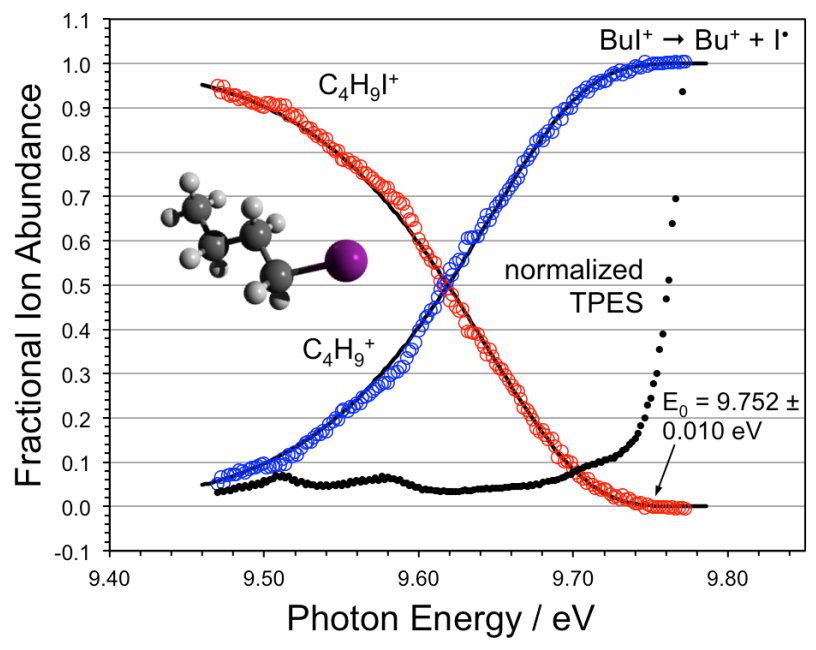


c)

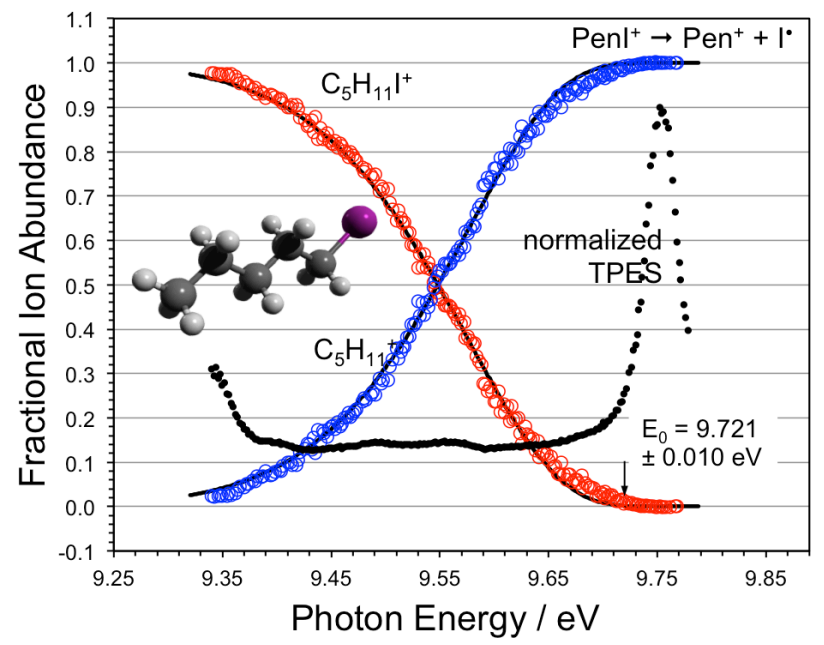

d)

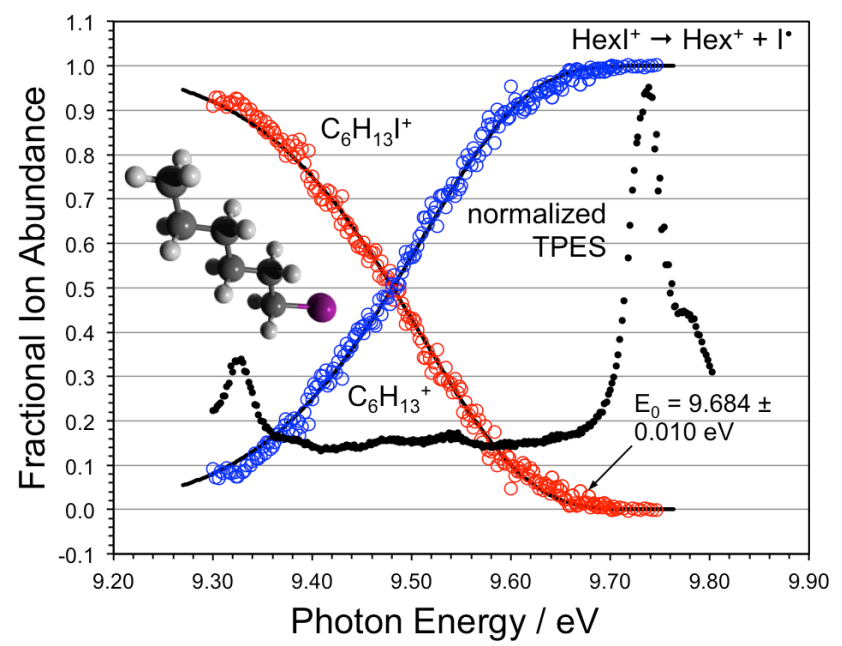

Figure 4. Breakdown diagrams for I loss from the four iodoalkanes, (a) $1-\mathrm{C}_{3} \mathrm{H}_{7} \mathrm{I}^{+}$, (b) $1-\mathrm{C}_{4} \mathrm{H}_{9} \mathrm{I}^{+}$, (c) 1 $\mathrm{C}_{5} \mathrm{H}_{11} \mathrm{I}^{+}$, and (d) $1-\mathrm{C}_{6} \mathrm{H}_{13} \mathrm{I}^{+}$. Red and blue open circles are experimental ion abundances, while solid black lines show the RRKM modeled breakdown curves. Solid black circles show the (normalized) threshold photoelectron spectra, i.e. the total threshold photoelectron signal.

The role of hindered rotation. One of the goals of this study was to evaluate the effect of internal hindered rotations on the internal energy distribution of the neutral precursor molecule, and, hence, on that of the parent ion. As discussed before, the shape of the internal energy distribution of the parent ion generally follows the energy distribution of the precursor molecule, particularly in non-resonant threshold photoionization in Franck-Condon gaps. This has been confirmed for over a hundred systems and only a few exceptions have been found, such as the preferential dissociative photoionization of water ${ }^{59}$ and the "colder" parent ions produced in resonant ionization in the TPES peaks as discussed previously. Iodoalkanes exhibit lowbarrier hindered rotations around the $\mathrm{C}-\mathrm{C}$ axes and the density-of-states function depends on whether these internal modes are handled as vibrations or hindered rotations. Among these degrees of freedom, the most important one is the lowest-barrier methyl rotor. Recently, we have shown that in the case of methanol and its isotopologues, a good breakdown curve fit close to 
onset could only be obtained by treating the methyl torsion as a hindered rotor. ${ }^{60}$ In other studies, however, we have seen cases where treating the methyl torsion as harmonic vibrator yielded superior fits. ${ }^{61}$

Table 1. Comparison of the RRKM models with and without methyl Pitzer rotor approximation in iodopropane. The first and third lines correspond to fits obtained with relaxed model temperature, while the second and fourth row data were obtained modeling with room temperature.

\begin{tabular}{llll} 
& $E_{0}(\mathrm{eV})$ & $T / \mathrm{K}$ & Error \\
\hline \multirow{2}{*}{ Vibrator } & 9.824 & 268 & 0.0720 \\
& 9.840 & 298 & 0.0755 \\
\multirow{3}{*}{ Pitzer rotor } & 9.836 & 274 & 0.0724 \\
& 9.848 & 298 & 0.0775
\end{tabular}

The internal energy distribution of iodopropane is most affected by the methyl rotation among the samples studied herein. Its breakdown diagram and TOF distribution were modeled with and without one hindered methyl rotor, treating the methyl rotation as a Pitzer rotor. ${ }^{47,62}$ Table 1 shows the quality of the fits as well as the difference in the optimized appearance energy, listing the optimized appearance energy $\left(E_{0}\right)$, and the overall least-squares-fit error of the model at both the optimized temperature $\left(T_{\mathrm{opt}}\right)$ as well as at the presumed experimental sample temperature $(298 \mathrm{~K})$. While the optimized temperature is closer to room temperature when assuming a hindered methyl rotor in the neutral density of states calculation, the fit error also increases. In other words, the inclusion of the internal rotation makes the fit more sensitive to the assumed temperature. Similar, but smaller effects have been observed in the larger alkyl chain samples, as well. In conclusion, there is little experimental evidence for or against the Pitzer 
rotor treatment of the methyl internal rotor and our choice of using the $E_{0}$ results obtained from the hindered rotor models with relaxed sample temperature is based on the better fit quality very close to the onset.

Heptyl iodide. The dissociative photoionization of heptyl iodide never yielded $100 \%$ Iloss fragment, as opposed to the shorter chain alkyliodides. The breakdown curves in Figure 5ab show that the molecular ion, $\mathrm{C}_{7} \mathrm{H}_{15} \mathrm{I}^{+}$disappears at $9.69 \mathrm{eV}$, with the iodine-loss product $\mathrm{C}_{7} \mathrm{H}_{15}{ }^{+}$ion being the first fragment. The slope of the fragment ion breakdown curves gives clues to the further mechanism of dissociative photoionization. ${ }^{63}$ The quickly rising $\mathrm{C}_{4} \mathrm{H}_{9}{ }^{+}$signal, for instance, indicates that the butyl cation is not a product of a competing dissociation reaction from the molecular ion, rather a sequential dissociation product of the heptyl cation. The fractional abundance of the dominant butyl ion declines as the propyl cation appears at about $10.7 \mathrm{eV}$. The slowly rising slope of the propyl cation's relative abundance is clear sign that this ion is formed from the heptyl ion, in parallel with the formation of the butyl cation. At higher energies, other minor channels also open up, leading to the $\mathrm{C}_{5} \mathrm{H}_{11}{ }^{+}$and $\mathrm{C}_{4} \mathrm{H}_{7}{ }^{+}$ions, but the relative abundance of these ions is less than $3 \%$, and $2 \%$, respectively.

a)

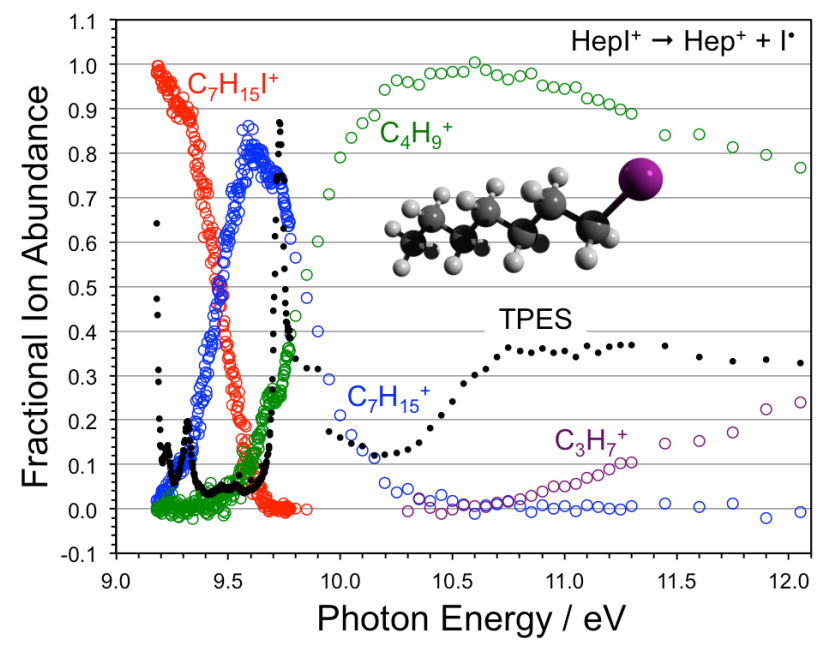

b)

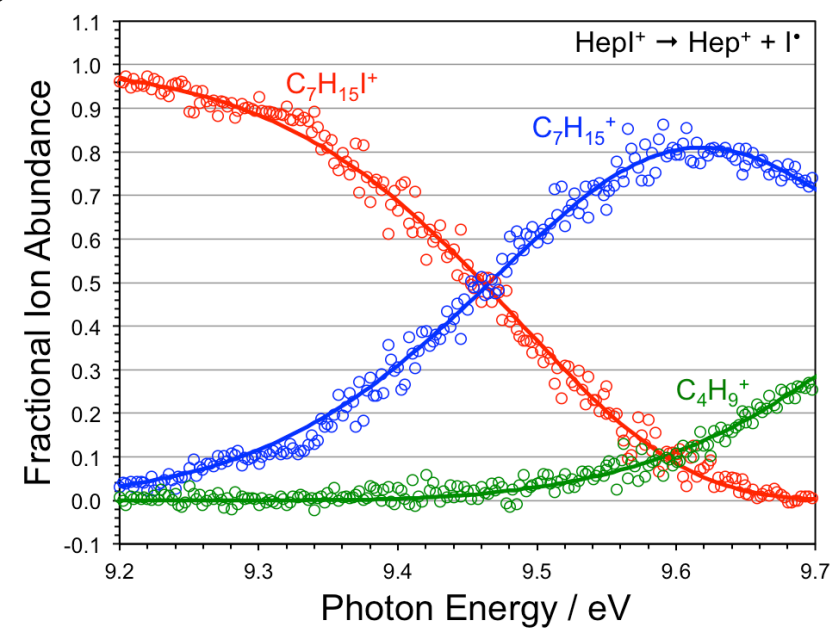

Figure 5a-b: Fractional ion abundances as function of photon energy (breakdown curves) in the 1-iodo 
heptane iPEPICO measurement. The threshold photoelectron spectrum (black dots) is show together with the zoomed-out breakdown curves in a), while the low-energy part of the breakdown curves is shown in b) together with the results of the RRKM modeling (solid lines).

The threshold photoelectron spectrum of heptyl iodide is shown in Figure 5a. At $9.35 \mathrm{eV}$, the sharp peak in the TPES is accompanied by a hardly noticeable break in the otherwise smooth molecular ion relative abundance. More pronounced is the effect of the intense TPES peak at 9.8 $\mathrm{eV}$, which is isoenergetic with a significant dip in the $\mathrm{C}_{4} \mathrm{H}_{9}{ }^{+}$ion ratio. As at this energy, the molecular ion is already $100 \%$ dissociated, the inverse of this dip appears in the ratio of the other major product ion at this photon energy, $\mathrm{C}_{7} \mathrm{H}_{15}{ }^{+}$. This illustrates once again that resonant ionization to an ionic state can have internal energy dependent cross-sections, which lead to a lowering of the mean internal energy of the photoion and, consequently, to a change in the branching ratios favoring the more stable fragment ions. In order to get a reliable estimate for the appearance energy of the first, iodine-loss dissociation channel, we have performed a similar RRKM modeling as for the shorter iodoalkanes. As the consecutive alkyl cation fragmentation channel is already open before the disappearance of the parent ion, this consecutive reaction was also included in the RRKM modeling but its fitted appearance energy is probably not reliable as it depends strongly on the (experimentally not accessible) value of the iodoheptyl isomerization energy. The $0 \mathrm{~K}$ appearance energy of the iodine-loss channel was obtained as $9.688 \pm 0.015 \mathrm{eV}$. Based on the markedly lower shift in the crossover energy, and, as will be discussed later, the 2heptyl cation not being the most stable fragment ion, it is unclear if this appearance energy corresponds to the 1-iodoheptane $\rightarrow 2$-iodoheptane isomerization transition state in the cation, or if a new rearrangement channel opens up with comparable activation energy. 
Table 2. Summary of the auxiliary and derived thermochemical data for the five iodoalkane species evaluated in this study.

\begin{tabular}{|c|c|c|c|}
\hline Molecule & $E_{0} / \mathrm{eV}$ & IE / eV & Rev. Barrier (eV) \\
\hline \multirow{3}{*}{$\mathrm{C}_{3} \mathrm{H}_{7} \mathrm{I}$} & $9.836 \pm 0.010^{\mathrm{a}}$ & $9.25^{\mathrm{d}}$ & \multirow{2}{*}{$0.16^{\mathrm{a}}$} \\
\hline & $9.8332 \pm 0.0017^{\mathrm{b}}$ & $9.26 \pm 0.005^{\mathrm{e}}$ & \\
\hline & $9.84 \pm 0.01^{\mathrm{c}}$ & $9.26^{\mathrm{f}, \mathrm{g}}$ & $0.16^{, 1}$ \\
\hline \multirow{3}{*}{$\mathrm{C}_{4} \mathrm{H}_{9} \mathrm{I}$} & $9.752 \pm 0.010^{\mathrm{a}}$ & $9.23^{\mathrm{d}, \mathrm{f}, \mathrm{j}, \mathrm{h}}$ & \multirow{2}{*}{$0.30^{\mathrm{a}}$} \\
\hline & $9.7544 \pm 0.0045^{b}$ & $9.23 \pm 0.005^{\mathrm{e}}$ & \\
\hline & $9.74 \pm 0.02^{1}$ & $9.21 \pm 0.01^{\mathrm{k}}$ & $0.27^{\mathrm{n}}$ \\
\hline \multirow{3}{*}{$\mathrm{C}_{5} \mathrm{H}_{11} \mathrm{I}$} & \multirow{3}{*}{$9.721 \pm 0.010^{\mathrm{a}}$} & $9.22,{ }^{d}$ & \multirow{3}{*}{$0.30^{\mathrm{a}}$} \\
\hline & & $9.18 \pm 0.01^{\mathrm{e}}$ & \\
\hline & & $9.20,{ }^{f} 9.18^{h}$ & \\
\hline \multirow{3}{*}{$\mathrm{C}_{6} \mathrm{H}_{13} \mathrm{I}$} & \multirow{3}{*}{$9.684 \pm 0.010^{\mathrm{a}}$} & $9.19,^{d}$ & \multirow{3}{*}{$0.35^{\mathrm{a}}$} \\
\hline & & $9.20,^{\mathrm{f}}$ & \\
\hline & & $9.18^{\mathrm{h}}$ & \\
\hline $\mathrm{C}_{7} \mathrm{H}_{15} \mathrm{I}$ & $9.688 \pm 0.015^{\mathrm{a}}$ & $9.17^{\mathrm{d}}$ & \\
\hline \multicolumn{4}{|c|}{$\begin{array}{l}{ }^{a} \text { This study. }{ }^{b} \text { Park et al. }{ }^{27,28}{ }^{\mathrm{c}} \text { Rosenstock et al. }{ }^{11 \mathrm{~d}} \text { Novak et al. }{ }^{37}{ }^{30} \text { Cocksey et al. }{ }^{34 \mathrm{f}} \text { Boschi } \\
\text { and Salahub }{ }^{35} \text { g Carlson et al. }{ }^{36 \mathrm{~h}} \text { Luo and Pacey }{ }^{38 \mathrm{i}} \text { Brand and Baer }{ }^{25 \mathrm{j}} \text { Kimura et al. }{ }^{64 \mathrm{k}} \text { Oliveira } \\
\text { et al. }{ }^{26}\end{array}$} \\
\hline
\end{tabular}

Appearance energies and derived energetics. Using the Novak ${ }^{37}$ adiabatic ionization energy values, the effective potential energy well of the alkyliodide cations has been found to be $0.59,0.52,0.50,0.49 \mathrm{eV}$, and $0.52 \mathrm{eV}$ in $\mathrm{C}_{3} \mathrm{H}_{7} \mathrm{I}^{+}, \mathrm{C}_{4} \mathrm{H}_{9} \mathrm{I}^{+}, \mathrm{C}_{5} \mathrm{H}_{11} \mathrm{I}^{+}, \mathrm{C}_{6} \mathrm{H}_{13} \mathrm{I}^{+}$, and $\mathrm{C}_{7} \mathrm{H}_{15} \mathrm{I}^{+}$, respectively. The decreasing trend from propyl to hexyl iodide confirms that as the alkyl chain length increases and the alkyl-iodine bond energy decreases because of inductive effects, the isomerization barrier decreases, too. The slight reversal in the heptyl iodide activation energy may be related to other isomerization pathways opening up as it is not clear which isomer ion the 
$1-\mathrm{C}_{7} \mathrm{H}_{15} \mathrm{I}^{+}$cation will fragment into. Since tunneling effects would lead to significantly metastable parent ions, the experimentally observed small kinetic shifts also indicate that the effect of $\mathrm{H}$-atom tunneling across the isomerization barrier is negligible. ${ }^{65}$ This is not quite unexpected, as H-migration is mediated by the leaving iodine atom, which will inhibit tunneling across the barrier. In order to interpret the experimental appearance energies in terms of reverse barriers, the question of the final product ion still has to be addressed.

[1]

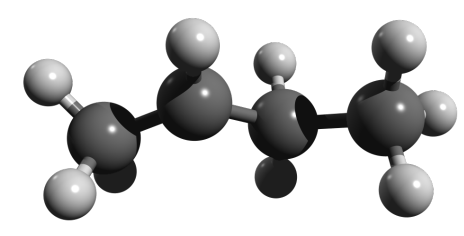

[2]

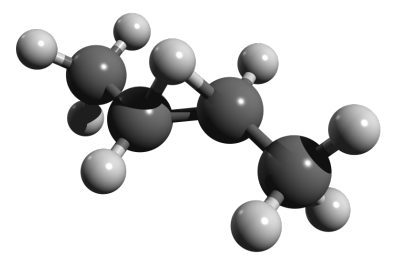

[3]

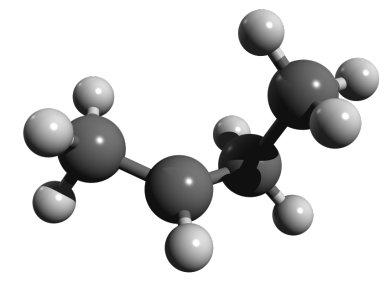

Figure 6. Three possible 2-butyl cation structures: [1] the classical one, [2] the bridged structure, and [3] a kinked carbon chain structure.

At the CBS-QB3 level of theory, the 2-alkyl cation is more stable than the 1-alkyl cation by $32.2 \mathrm{~kJ} \mathrm{~mol}^{-1}$ (propyl ion) to $40.7 \mathrm{~kJ} \mathrm{~mol}^{-1}$ (heptyl ion) (G4 values 33.7 to $42.4 \mathrm{~kJ} \mathrm{~mol}^{-1}$ ), and the 2-alkyl cations are also more stable than the 3-alkyl cations, where applicable. The only exception is the heptyl cation, in which the 3-heptyl and 4-heptyl ions are calculated to be 3.9 and $1.6 \mathrm{~kJ} \mathrm{~mol}^{-1}$ more stable than the 2-heptyl cation, respectively (CBS-QB3 values). The structure of the 2-butyl cation, however, poses further questions. Shimasaki et al. discussed two different minima, ${ }^{66}$ a bridged one and a kinked structure, shown as structures [2] and [3] in Figure 6. There is a third, straightforward structure [1], which is in fact a conformer of [3]. Density functional theory predicts structures [1] and [3] as minima and the $C_{2}$ symmetry [2] as a transition state for the $[\mathbf{1}] \rightarrow[\mathbf{1}]^{\prime}$ interconversion, lying at $2.5 \mathrm{~kJ} \mathrm{~mol}^{-1}$ higher in electronic energy. At the MP2 level, [1] is not a minimum, only [2] and [3] are. Similarly, at the CCSD/cc- 
pVTZ level of theory, the electronic energy is stabilized by $5.3 \mathrm{~kJ} \mathrm{~mol}^{-1}$ when the hydrogen atom is moved to the optimized bridge position in [2], from the B3LYP-optimized [1] structure. The G4, CBS-QB3 and $\mathrm{W} 1 \mathrm{U}^{12}$ composite methods predict the conformers [1] and [3] to lie 6.0-7.5 $\mathrm{kJ} \mathrm{mol}^{-1}$ above the bridged minimum [2], when [2] is optimized to the DFT transition state. CBS-APNO, which contains a QCISD geometry optimization, converges to [2] even from [1] as the starting point, however, it predicts the kinked structure [3] to be the most stable even if by only $0.2 \mathrm{~kJ} \mathrm{~mol}^{-1}$ with respect to [2]. Based on the agreement between the other composite methods with respect to the stability of [1-3], we conclude that this result is most likely an artifact, and, in the 2-butyl cation, the bridged structure [2] appears to be more stable by $6-7 \mathrm{~kJ}$ $\mathrm{mol}^{-1}$ relative to the isomers with only localized H-atoms. From 1-heptyl iodide, the 3- and 4heptyl cations are also viable fragment ion structures, which may well be accessible at the dissociative photoionization threshold and the experimental $E_{0}$ value may correspond to an isomerization barrier towards the 3- or 4-heptyl cations, slightly contradicting the experimental appearance energy trend from propyl to hexyl iodide.

Table 3. Isodesmic reaction energies at $0 \mathrm{~K}$ in $\mathrm{kJ} \mathrm{mol}^{-1}$, and the derived dissociative photoionization energies in $\mathrm{eV}$.

\begin{tabular}{lccccc}
\hline & $\begin{array}{c}\text { PrH }+\mathrm{R}^{+} \rightarrow \mathrm{RH}+\mathrm{Pr}^{+} \\
\mathrm{R}=\end{array}$ & $\mathrm{CBSI}+\mathrm{RH} \rightarrow \mathrm{RI}+\mathrm{PrH}$ & $\begin{array}{c}\text { Derived dissociative } \\
\text { photoionization } \\
\text { energy }^{a} / \mathrm{eV}^{2}\end{array}$ \\
\hline $\mathrm{Me}$ & -252.4 & -257.9 & 14.4 & 21.2 & $12.141^{b}$ \\
$\mathrm{Et}$ & -76.2 & -75.9 & 1.1 & 3.3 & $10.453^{b}$ \\
$\mathrm{Bu}$ & 20.6 & 19.7 & 0.7 & -0.6 & 9.454 \\
$\mathrm{Pe}$ & 25.4 & & -0.7 & -1.1 & 9.418 \\
$\mathrm{Hex}$ & 33.7 & & -0.4 & -1.3 & 9.329 \\
$\mathrm{Hep}$ & 36.9 & & -1.0 & -1.4 & 9.303 \\
\hline
\end{tabular}


${ }^{a}$ Based on the CBS-QB3 and DFT results and a 1-PrI dissociative photoionization energy of $9.675 \mathrm{eV}$, as derived in the text. ${ }^{b}$ C.f. literature values of 12.248 and $10.534 \mathrm{eV}$ for iodomethane and-ethane, respectively.

The isodesmic reaction energy calculations connect the I-loss dissociative photoionization energies of the different samples. Three anchors are possible, namely the $E_{0}$ in iodomethane, measured at $12.248 \pm 0.003 \mathrm{eV},{ }^{23}$ that in ethyl iodide, at $E_{0}=10.534 \pm 0.008 \mathrm{eV}{ }^{24}$ or the reaction energy of $1-\operatorname{PrI} \rightarrow i-\operatorname{Pr}^{+}+\mathrm{I}+\mathrm{e}^{-}$, calculated at $9.675 \mathrm{eV}$. The latter value is based on the room temperature heat of formation of iodopropane, $-27.8 \mathrm{~kJ} \mathrm{~mol}^{-1},{ }^{31}$ converted to -3.2 $\mathrm{kJ} \mathrm{mol}^{-1}$ at $0 \mathrm{~K}$ using the calculated thermal enthalpy of $14.8 \mathrm{~kJ} \mathrm{~mol}^{-1}$, as well as the isopropyl cation heat of formation of $\Delta_{\mathrm{f}} H^{\ominus}{ }_{0 \mathrm{~K}}=823.1 \pm 0.5 \mathrm{~kJ} \mathrm{~mol}^{-1},{ }^{67}$ and the iodine atom heat of formation of $107.16 \mathrm{~kJ} \mathrm{~mol}^{-1}{ }^{68}$ There is significant scatter in the I-transfer reaction energies depending on the anchor point chosen, and our decision to choose the propyl as anchor is based on two pieces of circumstantial evidence. First, this way the MP2 and DFT I-transfer energies disagree the least in the larger iodoalkanes, and second, the measured I-loss onset and the literature based I-loss dissociative photoionization energy imply a reverse barrier of $15.6 \mathrm{~kJ} \mathrm{~mol}^{-}$ ${ }^{1}$, in good agreement with the Rosenstock value of $15.4 \mathrm{~kJ} \mathrm{~mol}^{-1}(160 \mathrm{meV}) .{ }^{11} \mathrm{DFT}$ results are still superior to the MP2 when compared with experimental data on iodomethane and -ethane, and are used in the reverse barrier calculations. CBS-QB3 and CBS-APNO agree quite well for the H-transfer reactions in $\mathrm{R}=\mathrm{Me}$, $\mathrm{Pr}$ and $\mathrm{Bu}$, for which $\mathrm{CBS}-\mathrm{APNO}$ results are available, supporting the choice of CBS-QB3 reaction energies in the dissociative photoionization energy calculations. The difference between the derived values (Table 3) and the measured appearance energies yields the reverse barrier in dissociative photoionization, namely 28.8, 29.2, 34.2, and $37.2 \mathrm{~kJ} \mathrm{~mol}^{-1}$ in 1-butyl, pentyl, hexyl, and heptyl iodide, respectively, when the 2-heptyl cation is assumed to be the product ion. Based on the scatter of the ab initio results and the 
experimental uncertainties, these values are probably accurate to within $3-4 \mathrm{~kJ} \mathrm{~mol}^{-1}$, and the reverse barrier in 1-iodobutane cation compares favorably with the Oliveira et al. result of $26 \mathrm{~kJ}$ $\mathrm{mol}^{-1} \cdot 26$

Such accuracy is not to be expected from direct energy calculations. Still, even the DFT reverse barrier calculations on the ion surface yield much higher values than the experimental results, namely from 47.9 to $59.6 \mathrm{~kJ} \mathrm{~mol}^{-1}$ for propyl to heptyl iodide. The derived computed appearance energies decrease from 10.148 to $10.035 \mathrm{eV}$ with increasing carbon chain length, again much higher than observed experimentally. Using MP2 further increases the discrepancy, predicting the 1-iodopropane appearance energy at $10.462 \mathrm{eV}$. The simplest way to account for spin-orbit coupling, a major source of error, is to calculate e.g. the $\operatorname{PrI} \rightarrow \operatorname{Pr}^{+}+1 / 2 \mathrm{I}_{2}$ energy, and add the experimental $\mathrm{I}_{2}$ bond energy, $148.816 \mathrm{~kJ} \mathrm{~mol}^{-1}{ }^{68}$ thereto. The results, 10.323 and 10.655 $\mathrm{eV}$ for PrI using DFT and MP2, respectively, are more than $0.7 \mathrm{eV}, 70 \mathrm{~kJ} \mathrm{~mol}^{-1}$ higher than expected. The DFT calculated ionization energies, on the other hand, are consistently only by 0.21-0.22 eV higher than the measured ones across the series. In summary, it appears that standard computational chemistry approaches break down for such open shell systems with a heavy atom rather substantially.

\section{Conclusions}

Unimolecular dissociations of energy selected $1-\mathrm{C}_{3} \mathrm{H}_{7} \mathrm{I}^{+}, 1-\mathrm{C}_{4} \mathrm{H}_{9} \mathrm{I}^{+}, 1-\mathrm{C}_{5} \mathrm{H}_{11} \mathrm{I}^{+}, 1-\mathrm{C}_{6} \mathrm{H}_{13} \mathrm{I}^{+}$ and $1-\mathrm{C}_{7} \mathrm{H}_{15} \mathrm{I}^{+}$ions were studied using iPEPICO spectroscopy. All of the iodoalkane molecular ions exhibited somewhat slow dissociations at threshold, indicated by TOF spectra with asymmetric daughter ion peaks. Based on correlations between the breakdown diagrams and the threshold photoelectron spectra, we have confirmed the phenomenon that resonant threshold 
photoionization cross-sections are often larger for colder neutrals, previously reported for iodomethane.

With RRKM modeling of the TOF spectra and breakdown curves of the lighter four iodoalkanes, the alkyl ion $0 \mathrm{~K}$ appearance energies were determined to be $9.836 \pm 0.010,9.752 \pm$ $0.010,9.721 \pm 0.010,9.684 \pm 0.010 \mathrm{eV}$, and $9.688 \pm 0.015 \mathrm{eV}$ for $n$-propyl to $n$-heptyl iodide ions, respectively. Up to hexyl iodide, these were confirmed to correspond to isomerization barriers leading to 2-haloalkande cations, which subsequently dissociate yielding the closed shell 2-alkyl cation and an iodine atom. Using literature adiabatic ionization energies, the alkyliodide cation potential energy well depth was calculated to be $56.5,50.4,48 .{ }_{3}, 47.6$ and $50 \mathrm{~kJ} \mathrm{~mol}^{-1}$ in $\mathrm{C}_{3} \mathrm{H}_{7} \mathrm{I}^{+}, \mathrm{C}_{4} \mathrm{H}_{9} \mathrm{I}^{+}, \mathrm{C}_{5} \mathrm{H}_{11} \mathrm{I}^{+}, \mathrm{C}_{6} \mathrm{H}_{13} \mathrm{I}^{+}$, and $\mathrm{C}_{7} \mathrm{H}_{15} \mathrm{I}^{+}$ions, respectively. With the help of isodesmic reaction energies, anchored to the I-loss dissociative photoionization energy in propyl iodide, the dissociative photoionization energies were also determined, which, together with the measured appearance energies, confirm the reverse barrier in propyl iodide at $15.6 \mathrm{~kJ} \mathrm{~mol}^{-1}$, and yield it as $28.8,29.2$, and $34.2 \mathrm{~kJ} \mathrm{~mol}^{-1}$ in the butyl to hexyl iodide cations.

In heptyl iodide, the dissociation scheme was found to be different from those of the lighter analogs. Sequential dissociation of the first fragment ion, $\mathrm{C}_{7} \mathrm{H}_{15}{ }^{+}$leads to $\mathrm{C}_{4} \mathrm{H}_{9}{ }^{+}, \mathrm{C}_{5} \mathrm{H}_{11}{ }^{+}$, and $\mathrm{C}_{3} \mathrm{H}_{7}{ }^{+}$ions in competitive dissociation processes, dominated at low energies by the $\mathrm{C}_{4} \mathrm{H}_{9}{ }^{+}$ cation. This may indicate new, lower-energy rearrangement channels opening up due to the flexibility of the longer carbon chain.

In the modeling of the PEPICO data using statistical energy distributions and rate theory, the role of hindered rotation of the methyl group was also explored in propyl iodide. Contrary to earlier studies on amines ${ }^{146}$ and methanol, ${ }^{145}$ there was little experimental evidence for or against the hindered rotor treatment. The most likely cause of this is the kinetic broadening because of 
the slow isomerization step preceding dissociation. We have also shown that widely used and proven quantum chemical approaches have significantly lower accuracy when applied to open shell systems containing iodine, a period 5 atom, while a careful combination of experimentally obtained activation energies together with isodesmic reaction enthalpies on the closed-shell systems yields reverse barriers that are likely much more accurate.

\section{Acknowledgements}

This material is based upon work supported by the National Science Foundation under CHE1266407. The financial support by the Swiss Department of Energy (BFE \#100708) is also gratefully acknowledged. The experimental work was carried out at the VUV beamline of the Swiss Light Source of the Paul Scherrer Institut.

\section{References}

(1) Blanksby, S. J.; Ellison, G. B. Acc. Chem. Res. 2003, 36, 255-263.

(2) Berkowitz, J.; Ellison, G. B.; Gutman, D. J. Phys. Chem. 1994, 98, 2744-2765.

(3) Benson, S. W. J. Chem. Educ. 1965, 42, 502-518.

(4) Kerr, J. A. Chem. Rev. 1966, 66, 465-500.

(5) Izgorodina, E. I.; Coote, M. L.; Radom, L. J. Phys. Chem. A 2005, 7558-7566.

(6) Coote, M. L.; Pross, A.; Radom, L. Org. Lett. 2003, 4689-4692.

(7) Riley, K. E.; Hobza, P. Cryst. Growth Des. 2011, 11, 4272-4278.

(8) Chuang, P. Y.; Lee, W. L.; Teng, T. F.; Lai, Y. H.; Hung, W. H. J. Phys. Chem. C 2009, 17447-17454.

(9) Noller, B.; Margraf, M.; Schröter, C.; Schultz, T.; Fischer, I. Phys. Chem. Chem. Phys. 2009, 11, 5353-5357.

(10) Bento, A. P.; Bickelhaupt, F. M. J. Org. Chem. 2008, 73, 7290-7299.

(11) Rosenstock, H. M.; Buff, R.; Ferreira, M. A. A.; Lias, S. G.; Parr, A. C.; Stockbauer, R.; Holmes, J. L. J. Am. Chem. Soc. 1982, 104, 2337-2345.

(12) Martin, J. M. L.; de Oliveira, G. J. Chem. Phys. 1999, 111, 1843-1856.

(13) Tajti, A.; Szalay, P. G.; Császár, A. G.; Kállay, M.; Gauss, J.; Valeev, E. F.; Flowers, B. A.; Vázquez, J.; Stanton, J. F. J. Chem. Phys. 2004, 121, 11599-11613.

(14) Puzzarini, C.; Barone, V. Int. J. Quantum Chem. 2009, 110, 637-655.

(15) Wimmer, E.; Najafabadi, R.; Young, George A., J.; Ballard, J. D.; Angeliu, T. M.; Vollmer, J.; Chambers, J. J.; Niimi, H.; Shaw, J. B.; Freeman, C.; Christensen, M.; Wolf, W.; Saxe, P. J. Phys. Condens. Matter 2010, 22, 384215. 
(16) Harding, M. E.; Vázquez, J.; Gauss, J.; Stanton, J. F.; Kállay, M. J. Chem. Phys. 2011, $135,044513 / 1-044513 / 10$.

(17) Li, Y.; Zhou, W.; Zhang, J.; Li, S.; Gao, H.; Zhou, Z. Comput. Theor. Chem. 2011, 968, 64-70.

(18) Baer, T.; Walker, S. H.; Shuman, N. S.; Bodi, A. J. Phys. Chem. A 2012, 116, 2833-2844.

(19) Siebert, M. R.; Aquino, A. J. A.; de Jong, W. A.; Granucci, G.; Hase, W. L. Mol. Phys. 2012, 110, 2599-2609.

(20) Bodi, A.; Johnson, M.; Gerber, T.; Gengeliczki, Z.; Sztáray, B.; Baer, T. Rev. Sci. Instrum. 2009, 80, 034101.

(21) Johnson, M.; Bodi, A.; Schulz, L.; Gerber, T. Nucl. Instruments Methods Phys. Res. A 2009, 610, 597-603.

(22) Sztáray, B.; Bodi, A.; Baer, T. J. Mass Spectrom. 2010, 45, 1233-1245.

(23) Bodi, A.; Shuman, N. S.; Baer, T. Phys. Chem. Chem. Phys. 2009, 11, 11013-11021.

(24) Borkar, S.; Sztáray, B. J. Phys. Chem. A 2010, 114, 6117-6123.

(25) Brand, W. A.; Baer, T.; Klots, C. E. Chem. Phys. 1983, 76, 111-120.

(26) Oliveira, M. C.; Baer, T.; Olesik, S.; Ferreira, M. A. A. Int. J. Mass Spectrom. Ion Process. 1988, 82, 299-318.

(27) Park, S. T.; Kim, S. K.; Kim, M. S. J. Chem. Phys. 2001, 114, 5568-5576.

(28) Park, S. T.; Kim, S. K.; Kim, M. S. J. Chem. Phys. 2001, 115, 2492-2498.

(29) Mortimer, C. T.; Pritchard, H. O.; Skinner, H. A. Trans. Faraday Soc. 1952, 48, 220-228.

(30) Stull, D. R.; Westrum, E. F. J.; Sinke, G. The Chemical Thermodynamics of Organic Compounds; 1969; p. 865.

(31) Richard, L.; Gaona, X. Geochim. Cosmochim. Acta 2011, 75, 7304-7350.

(32) Domalski, E. S.; Hearing, E. D. J. Phys. Chem. Ref. Data 1993, 22, 805-1159.

(33) Benson, S. W.; Amano, A. J. Chem. Phys. 1962, 37, 197-198.

(34) Cocksey, B. J.; Eland, J. H. D.; Danby, C. J. J. Chem. Soc. 1971, 790-792.

(35) Boschi, R. A. A.; Salahub, D. R. Can. J. Chem. 1974, 52, 1217-1228.

(36) Carlson, T. A.; Gerard, P.; Pullen, B. P.; Grimm, F. A. J. Chem. Phys. 1988, 89, 14641468.

(37) Novak, I.; Klasinc, L.; Kovac, B.; McGlynn, S. P. J. Mol. Struct. 1993, 297, 383-391.

(38) Luo, Y. R.; Pacey, P. D. Int. J. Mass Spectrom. Ion Process. 1992, 112, 1992.

(39) Kimura, K.; Katsumata, S.; Achiba, Y. Handbook of HeI Photoelectron Spectra of Fundamental Organic Molecules; Japan Scientific Society: Tokyo, 1981.

(40) Sztáray, B.; Baer, T. Rev. Sci. Instrum. 2003, 74, 3763.

(41) Poliakoff, E. D.; Dehmer, P. M.; Dehmer, J. L.; Stockbauer, R. J. Chem. Phys. 1981, 75, 1568-1569.

(42) Tsai, B. P.; Werner, A. S.; Baer, T. JCP 1975, 63, 4384-4392.

(43) Brehm, B.; Eland, J. H. D.; Frey, R.; Kuestler, A. Int. J. Mass Spectrom. Ion Phys. 1973, 12, 197-211.

(44) Ralchenku, Y.; Kramida, A. E.; Reader, J. NIST Atomic Spectra Database.

(45) Bodi, A.; Sztáray, B.; Baer, T.; Johnson, M.; Gerber, T. Rev. Sci. Instrum. 2007, 78, 084102.

(46) Shuman, N. S.; Bodi, A.; Baer, T. J. Phys. Chem. A 2010, 114, 232-240.

(47) Baer, T.; Hase, W. L. Unimolecular Reaction Dynamics: Theory and Experiments; Oxford University Press: New York, 1996.

(48) Beyer, T.; Swinehart, D. R. Commun, ACM 1973, 16, 379-384. 
(49) Rice, O. K.; Ramsperger, H. C. J. Am. Chem. Soc. 1927, 49, 1617-1629.

(50) Kassel, L. S. J. Phys. Chem. 1928, 32, 225-242.

(51) Marcus, R. A.; Rice, O. K. J. Phys. Chem. 1951, 55, 894-908.

(52) Chai, J.-D.; Head-Gordon, M. Phys. Chem. Chem. Phys. 2008, 10, 6615-6620.

(53) Bergner, A.; Dolg, M.; Küchle, W.; Stoll, H.; Preuß, H. Mol. Phys. 1993, 80, 1431-1441.

(54) Martin, J. M. L.; Sundermann, A. J. Chem. Phys. 2001, 114, 3408.

(55) Peng, C.; Ayala, P. Y.; Schlegel, H. B.; Frisch, M. J. J. Comput. Chem. 1996, 17, 49-56.

(56) Montgomery, J. A.; Frisch, M. J.; Ochterski, J. W.; Petersson, G. A. J. Chem. Phys. 2000, $112,6532$.

(57) Ochterski, J. W.; Petersson, G. A.; Montgomery, J. A. J.Chem.Phys 1996, 104, 25982619.

(58) Curtiss, L. A.; Redfern, P. C.; Raghavachari, K. J. Chem. Phys. 2007, 126, 084108.

(59) Bodi, A.; Csontos, J.; Kallay, M.; Borkar, S.; Sztaray, B. Chem. Sci. 2014, 5, 3057-3063

(60) Borkar, S.; Sztáray, B.; Bodi, A. Phys. Chem. Chem. Phys. 2011, 13, 13009-13020.

(61) Bodi, A.; Kercher, J. P.; Bond, C.; Meteesatien, P.; Baer, T. J. Phys. Chem. A 2006, 110, 13425-13433.

(62) Pitzer, K. S. Quantum Chemistry; Prentice Hall: New York, 1953; Vol. 76.

(63) Hemberger, P.; Bodi, A.; Gerber, T.; Würtemberger, M.; Radius, U. Chemistry 2013, 19, 7090-7099.

(64) Kimura, K.; Katsumata, S.; Achiba, Y.; Matsumoto, H.; Ngakura, S. Bull. Chem. Soc. Jpn. 1973, 46, 373-380.

(65) Bodi, A.; Daniel Brannock, M.; Sztáray, B.; Baer, T. Phys. Chem. Chem. Phys. 2012, 14, 16047-16054.

(66) Shimasaki, T.; Nakayasu, K.; Shibata, M.; Yamaguchi, T. J. Chem. 2013, 2013, 406904.

(67) Stevens, W. R.; Bodi, A.; Baer, T. J. Phys. Chem. A 2010, 114, 11285-11291.

(68) Chase Jr., M. W. NIST-JANAF Thermochemical Tables; J. Phys. Chem. Ref. Data; 1998; Vol. Fourth, pp. 1-1951. 
Iodine Atom Loss Kinetics in Internal Energy Selected 1-Iodoalkane Cations by Imaging Photoelectron Photoion Coincidence Spectroscopy TOC Graphic

Imaging Photoelectron Photoion Coincidence Spectroscopy yields accurate energetics on the rearrangement barrier in alkyl iodide cations. With isodesmic quantum-chemical calculations on the thermochemical limits, the reverse barrier to dissociation can be derived. While direct quantum-chemical calculations on the transition state of open-shell iodine-containing species are usually inaccurate, the combined experimental-quantum chemical approach is likely to yield reliable data.
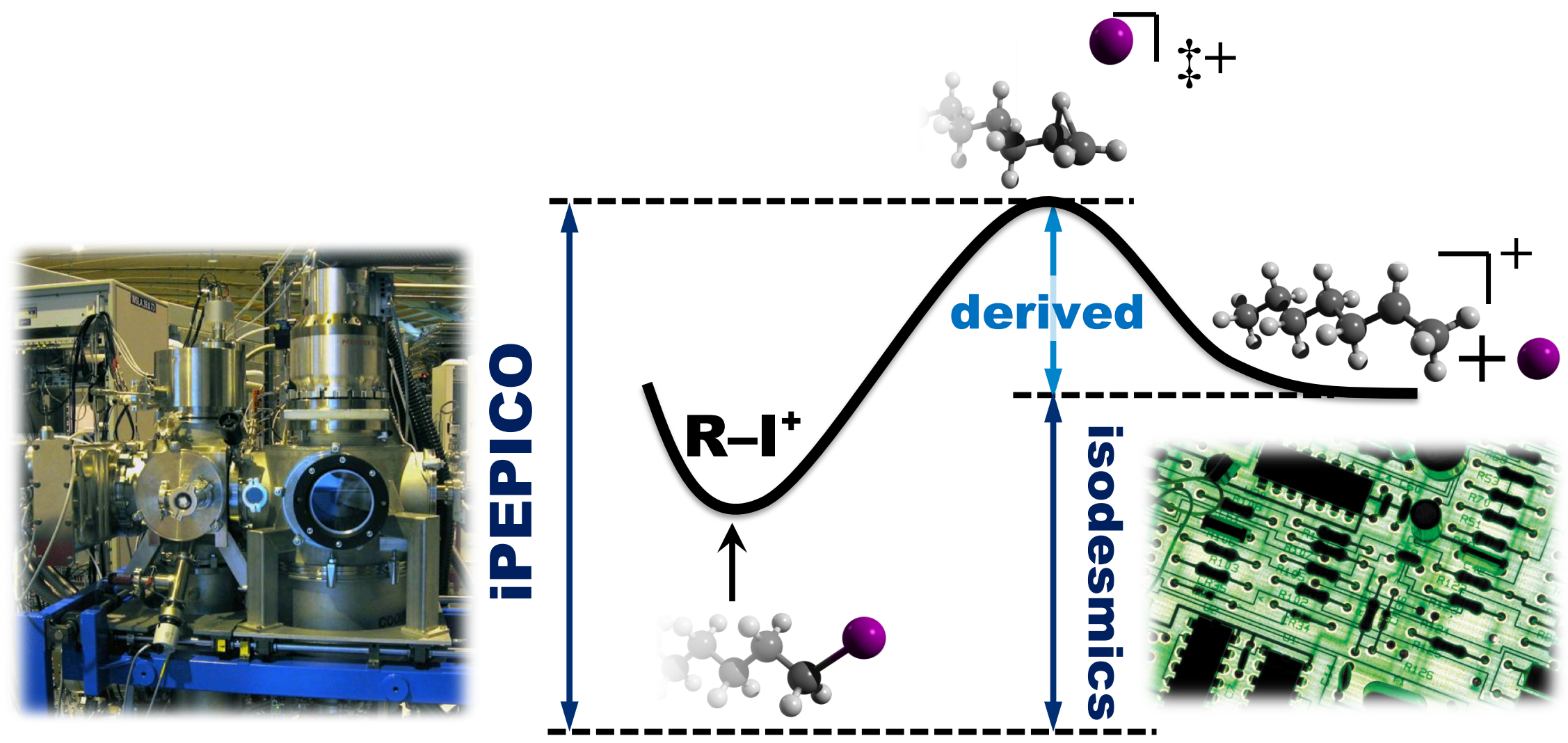